\title{
Military surgeons just want to have fun
}

\author{
Fred Weber, MD, JD, FACS
}

\author{
From the Department of Surgery (Retired), Drexel University, Philadelphia, Pa. \\ Disclosures: Author has nothing to disclose with regard to commercial support. \\ Received for publication June 6, 2016; accepted for publication June 9, 2016; available ahead of print July 12, \\ 2016. \\ Address for reprints: Fred Weber, MD, JD, FACS, 200 E Atlantic Blvd, Ocean City, NJ 08226 (E-mail: fweber. \\ mdjd@gmail.com) \\ J Thorac Cardiovasc Surg 2016;152:667-8 \\ $0022-5223 / \$ 36.00$ \\ Copyright (C) 2016 by The American Association for Thoracic Surgery \\ http://dx.doi.org/10.1016/j.jtcvs.2016.06.007
}

In their recent article, Helsel and colleagues ${ }^{1}$ detail the unique challenges facing military cardiothoracic surgeons with low index volume in elective thoracic surgery during and on return from deployment.

Hippocrates stated: "All those who desire to become a surgeon should go to war." 2 We are grateful for and value the service of military surgeons (Figure 1). Advances in surgery have been the product of armed conflict and these advances have been translated into civilian care. For example, the Civil War advanced the practice of amputation, ${ }^{3}$ World War I brought advances in the transport of injured persons, ${ }^{4}$ World War II brought about specialty care centers such as the Second Auxiliary Group for chest injuries, ${ }^{5}$ the Korean War introduced the mobile Army surgical hospital, ${ }^{6}$ and the Vietnam War advanced the practice of vascular surgery. ${ }^{7}$ Surgeons in the current Middle East conflicts are pioneering the concepts of acute tourniquets and critical care evacuation teams.

Although the surgeons caring for wounded soldiers develop the skills needed for this special practice, the volume needed for proficiency in elective cardiothoracic practice is lacking. It is established that performing a quantity of a specific procedure leads to competency in its performance. ${ }^{8}$ The authors note that a military surgeon's deployment may be up to 1 year. ${ }^{1}$ This absence from the elective practice of cardiothoracic surgery fosters degradation of operative and clinical competency. On return from deployment, unless sufficient clinical material is present further degradation of skills can be expected.

Military surgeons engage in 2 separate and distinct practices: that of deployment in the battle zone and that of peacetime/nondeployed practice. On return from deployment, integration into the routine practice of our specialty faces barriers. One barrier the authors note is the current environment of low cardiothoracic surgical volume at most military hospitals. ${ }^{1}$ The authors point out that as a result of policy changes in the military health care system over the past decade, more patients receive care in their local civilian network rather than at regionalized military medical centers.

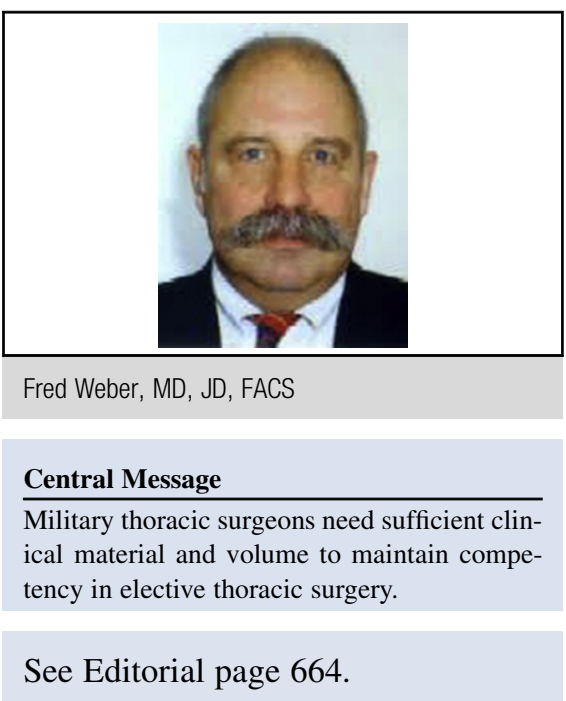

There are solutions to the problem of providing military surgeons with elective cardiothoracic surgery material on return from deployment. A successful collaboration exists, for example, between the San Antonio Military Medical Center and the South Texas Veterans Health Care System, wherein returning surgeons provide elective care and see a dramatic increase in surgical volume.

This model of collaboration between a military hospital and Veterans Affairs health systems can be emulated at facilities across the country. The authors state that, "Military cardiothoracic surgeons in peacetime provide care for service members, their families, and retirees." 1

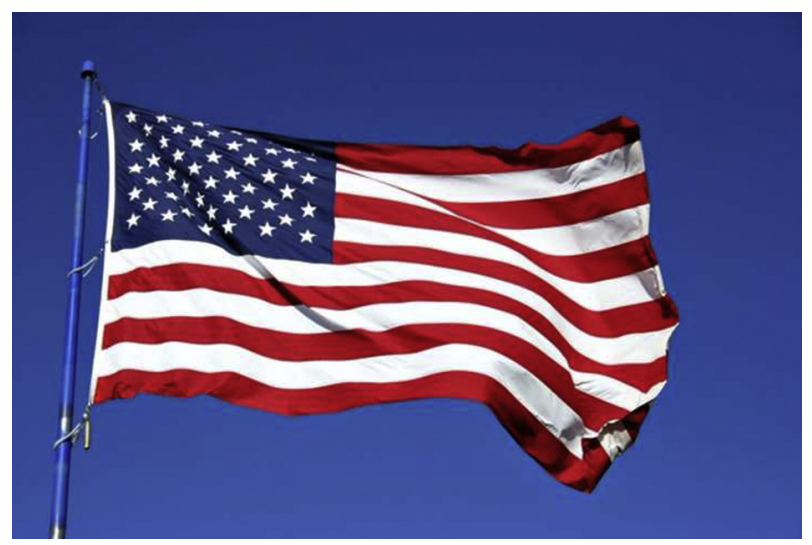

FIGURE 1. As a nation, we are grateful for and value the service of the military surgeons. 
This is a rich patient population for military surgeons in elective cardiothoracic practice. Implementation of this model in other centers would be a partial solution, although given the current environment of the US Department of Veterans Affairs, structuring this partnership may be a challenge.

Collaboration between military and civilian institutions can be explored for returning military surgeons, but both parties will face barriers of local practice patterns and administrative concerns.

The goal of all these efforts is to support military thoracic surgeons on return from deployment. It is perhaps the best way for the entire thoracic surgery community to thank military thoracic surgeons like the authors ${ }^{1}$ for their dedication, service, courage, and sacrifice.

\section{References}

1. Helsel BS, David EA, Antevil JL. Special considerations of military cardiothoracic surgeons. J Thorac Cardiovasc Surg. 2016:152:664-6.

2. Strauss MH, ed. Familiar medical quotations. Boston and Company: Little Brown; 1968:582.

3. Blaisdell FW. Medical advances during the Civil War. Presidential Address. Arch Surg. 1988:123:1045-50.

4. McCallum JE. Military medicine: from ancient times to the 21 st century. Santa Barbara: ABC-CLIO; 2008:11.

5. Brewer LA. The contributions of the Second Auxiliary Surgical Group to military surgery during World War II with special reference to thoracic surgery. Ann Surg. 1983:197:318-26.

6. King B, Jatoi I. The mobile Army surgical hospital (MASH): a military and surgical legacy. J Natl Med Assoc. 2005:97:648-56.

7. Levitsky S, James PM, Anderson RW, Hardaway RM III. Vascular trauma in Vietnam battle casualties: an analysis of 55 consecutive cases. Ann Surg. 1983; 197:318-26

8. Hillner B, Smith TJ, Desch CE. Hospital and physician volume or specialization and outcomes in cancer treatment: importance in quality of cancer care. J Clin Oncol. 2000;18:2327-40.

Access to The Journal of Thoracic and Cardiovascular Surgery Online is reserved for print subscribers!

Full-text access to The Journal of Thoracic and Cardiovascular Surgery Online is available for all print subscribers. To activate your individual online subscription, please visit The Journal of Thoracic and Cardiovascular Surgery Online, point your browser to http://www.mosby.com/jtcvs, follow the prompts to activate your online access, and follow the instructions. To activate your account, you will need your subscriber account number, which you can find on your mailing label (note: the number of digits in your subscriber account number varies from 6 to 10 ). See the example below in which the subscriber account number has been circled:

\section{Sample mailing label}

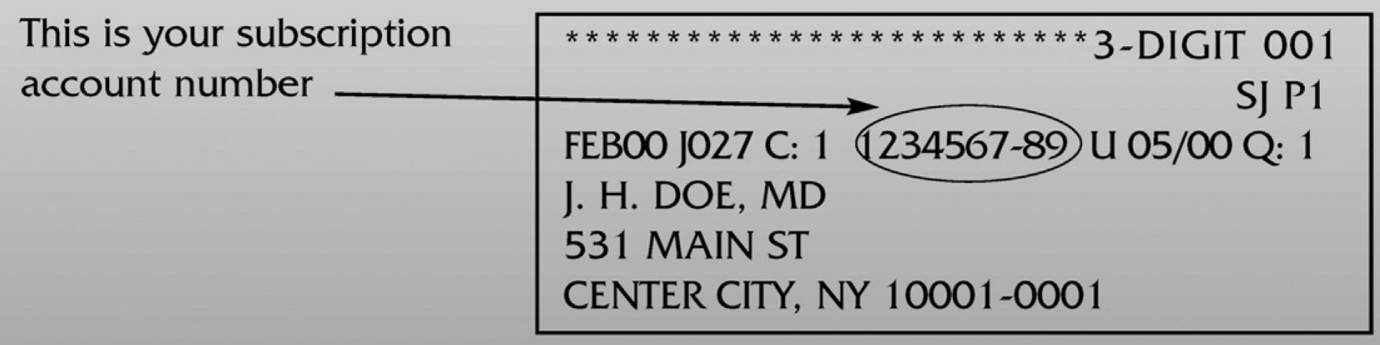

Personal subscriptions to The Joumal of Thoracic and Cardiovascular Surgery Online are for individual use only and may not be transferred. Use of The Journal of Thoracic and Cardiovascular Surgery Online is subject to agreement to the terms and conditions as indicated online. 